\section{Immigration and knowledge, education, and practices regarding chronic hepatitis $B$ in pregnancy}

\section{Seyed Moayed Alavian}

Baqiyatallah University of Medical Sciences, Tehran, Iran

I read with interest the article by Niu et al [1] and I wish to make the following comments. First, the overall knowledge of enrolled cases regarding measures of hepatitis $\mathrm{B}$ virus (HBV) is shown to be low, which may be related to the study methodology; however, the main limitation in this study was a low response rate that prevents drawing any conclusions.

Second, the global distribution of HBV infection varies significantly between countries, being low in the USA, Western Europe and Canada and high in some parts of Asia and Africa, with higher rates of vertical transmission in these regions. Socioeconomic and political factors, as well as internal wars in some parts of Asia and Africa, have lead to massive migration to areas in the world with low endemicity for HBV [2]. This event has significantly changed the burden of HBV in the USA and other countries with a low prevalence of HBV infection. Therefore, physicians should have knowledge of enrolled cases, including higher-risk and pregnant patients, and in particular people who have immigrated from countries with a high prevalence of HBV infection. Finally, there were no data regarding $\mathrm{HBV}$ vaccination in the enrolled cases; if the patients' HBV vaccination history and their ant-HBs antibody title had been reported, it would have been easy to predict their health precaution in practice and their knowledge regarding hepatitis B in pregnancy [3].

\section{References}

1. Niu B, Marzio DH, Fenkel JM, Herrine SK. 'Obstetricians' and 'gynecologists' knowledge, education, and practices regarding chronic hepatitis B in pregnancy. Ann Gastroenterol 2017;30: 670-674.

2. Sagnelli E, Alessio L, Sagnelli C, et al. Hepatitis B virus genotypes, epidemiological characteristics, and clinical presentation of HBV chronic infection in immigrant populations living in southern Italy. Hepat Mon 2017;17:e13260.

3. Azami M, Hafezi Ahmadi MR, Sayehmiri K. Hepatitis B vaccination efficacy in Iranian healthcare workers: a meta-analysis study. Hepat Mon 2017;17:e37781.

Baqiyatallah Research Center for Gastroenterology and Liver Diseases, Baqiyatallah University of Medical Sciences, Tehran, IR Iran, Director of Iran Hepatitis Network

Conflict of Interest: None

Correspondence to: Seyed Moayed Alavian MD, Professor of Medicine, Director of Iran Hepatitis Network, Baqiyatallah Research Center for Gastroenterology and Liver Diseases, Baqiyatallah University of Medical Sciences, Tehran, IR Iran, e-mail: Alavian@thc.ir

Received 2 February 2018; accepted 12 February 2018;

published online 15 March 2018

DOI: https://doi.org/10.20524/aog.2018.0246 